\title{
Paisagem natural e patrimônio cultural na região da Araucanía, Chile.
}

\author{
Natural landscape and cultural heritage \\ in the Araucanía region, Chile.
}

\author{
Giovanni de Farias Seabra
}

\begin{abstract}
RESUMO
O Chile é um país que exibe uma grande diversidade paisagística representada pelos variados níveis topográficos, nos diferentes tipos climáticos, na rica biodiversidade, e também a irregular ocupação humana. Nesse cenário, o presente trabalho enfoca a região de Araucanía, onde são evidenciadas distintas paisagens naturais, o patrimônio cultural agregado, bem como os segmentos e roteiros turísticos implantados, com destaque para o turismo etnocultural mapuche e o geoturismo. A pesquisa priorizou estudar os mecanismos de gestão das áreas protegidas, observando as ocorrências da gestão compartilhada e a oportunidade de serviços oferecidos à população local. $O$ processo investigativo adotou o procedimento metodológico integrado reunindo diferentes campos das ciências, como a Geografia Física, Geologia, Biologia, Ecologia, Paisagismo e o Turismo.
\end{abstract}

Palavras-chave: Áreas Protegidas; Paisagem Natural; Patrimônio Cultural; Ordenamento Territorial

\section{ABSTRACT}

The Chile is a country with a diverse landscape represented by varying topographic levels, different climate types, rich biodiversity and irregular human occupation. In this scenario, the present work focuses on the Araucanía region, where the different natural landscapes, the cultural heritage, as well as the tourist segments and itineraries implanted in the region, with emphasis on mapuche ethnocultural tourism. The research prioritized studying the management mechanisms of protected areas, observing the occurrences of shared management and the opportunity of services offered to the local population. The investigative process adopted the integrated methodological procedure bringing together different fields of science, such as Physical Geography, Geology, Biology, Ecology, Landscaping and Tourism.

Keywords: Protected Areas; Natural Landscape; Cultural Heritage; Territorial Planning

Doutor em Geografia, professor titular da Unversidade Federal da Paraíba. E-mail. gioseabra@gmail.com ORCID: http://orcid.org/00000002-8726-2710 


\section{INTRODUÇÃO}

Flanqueado pelo oceano Pacífico, a oeste, e a cordilheira dos Andes, a leste, o território chileno se prolonga em terras continentais sul-americanas por 4.300 quilômetros, desde a fronteira com o Peru até os limites meridionais da Terra do Fogo. A largura máxima do país alcança $175 \mathrm{~km}$; todavia sua área abrange porções do continente americano, do oceano Pacífico e do continente Antártico. Os pontos extremos se unem com a llha da Páscoa, encerrando um triângulo imaginário cobrindo uma área de 8 milhões de km².

A população do Chile se concentra, principalmente, no vale Central e, por outro lado, apresenta vazios demográficos, sobretudo no deserto de Atacama, ao norte, na cordilheira andina, a leste e nas regiões da Patagônia, Magalhães e Terra do Fogo, ao sul.

Segundo estimativas, o efetivo populacional chileno alcançou em 201918.762 .000 habitantes (COUNTRY METERS, 2019), concentrando as maiores densidades demográficas na região metropolitana de Santiago (394 hab/ $\mathrm{km}^{2}$ ) e Val Paraíso (93,9 hab./ $\mathrm{km}^{2}$ ). Por outro lado, os menores adensamentos são encontrados no deserto de Atacama (3,4 hab./ $\left.\mathrm{km}^{2}\right)$ e Região de Magalhães (1,1 hab./ $\left.\mathrm{km}^{2}\right)$. A população indígena da etnia mapuche alcança um milhão e quinhentos mil pessoas, o que corresponde a 9,1\% da população nacional. A maior parte da população indígena está localizada em áreas urbanas e as maiores concentrações são encontradas na Região Metropolitana de Santiago, em Temuco (Região de Araucanía) e Concepción (Região de Biobío). (REYES, 2019).

A Araucanía, objeto de estudo do presente trabalho, possui uma área de $31.842,3 \mathrm{~km}^{2}$, representando 4,2\% da superfície do país. A população regional é de 869.535 habitantes, equivalente a $5,8 \%$ da população nacional e a densidade atinge $27,3 \mathrm{hab} / \mathrm{km}^{2}$, ao passo que a população rural é de 281.127 pessoas, representando 32,3\% da população regional total, segundo estimativas em 2019. (GOBIERNO REGIONAL DE ARAUCANÍA, 2020).

As condições de habitabilidade mais adequadas estão situadas no terço central (Sentido N - S), e, por sua vez, no vale Central localizado entre as cordilheiras dos Andes e da Costa (33० lat. S e $40^{\circ}$ lat. S).

Convém destacar que $80 \%$ do território chileno é fortemente ondulado, onde ocorrem vulcões ativos, dificultando ou impedindo o estabelecimento humano. A esse fator, são 
acrescentados os extremos climáticos, a intensa atividade vulcânica e os frequentes terremotos e maremotos. Os mananciais hídricos são limitados, pois se originam nas elevadas montanhas e glaciares, percorrendo distâncias de até 100 quilômetros, quando se encontram com o oceano Pacífico. Por conseguinte, as regiões naturais, com escassa população, são as que ostentam a maior concentração de áreas silvestres protegidas, como os desertos, as cordilheiras e a Patagônia.

As unidades de conservação do Chile possuem exuberantes paisagens naturais e excepcional patrimônio cultural, cumprindo a função primordial de preservar os sítios geomorfológicos, paleontológicos, arqueológicos, a biodiversidade, os mananciais hídricos e os valores culturais dos grupos sociais residentes.

O Chile e o Brasil têm instrumentos e mecanismos para preservação dos bens naturais e do patrimônio cultural, a exemplo do Sistema Nacional de Unidades de Conservação (Brasil), vinculado ao Ministério do Meio Ambiente (MMA), e o equivalente chileno Sistema Nacional de Áreas Silvestres Protegidas del Estado (SNASPE), administrado pela Corporación Nacional Forestal, (CONAF). Contudo, tanto no Brasil como no Chile, os recursos, equipamentos e funcionários são insuficientes na administração e monitoramento das áreas protegidas. Ambos os países seguem o caminho da privatização dos serviços, os quais, por um lado suprem as lacunas abertas pelos governos federais e, por outro, acelera a escalada dos preços dos ingressos e serviços cobrados aos visitantes.

As áreas protegidas têm a função de conservação e proteção do meio ambiente, com aplicação de sistemas de gestão diferentes, de acordo com os objetivos da criação. Os parques nacionais, por exemplo, são áreas extensas de domínio da União que têm como objetivo básico a preservação de ecossistemas naturais de grande relevância ecológica e beleza cênica, possibilitando a realização de pesquisas científicas e o desenvolvimento de atividades de educação e interpretação ambiental, de recreação em contato com a natureza e de turismo ecológico (BRASIL, 2000). Os geoparques, por sua vez, possuem legislação e mecanismos complementares àqueles que normatizam as unidades de conservação, com ênfase nos aspectos geológico-geomorfológicos da paisagem, na geoconservação e no desenvolvimento sustentável. 
Contudo, falhas nas estratégias de planejamento e na execução dos planos de manejo e programas de ações impõem ameaças à integridade dos sistemas socioambientais que deveriam ser protegidos com a criação das unidades de conservação. Nesse contexto, surge o ecoturismo como instrumento ambientalmente conscientizador e mobilizador, cujos trabalhos desenvolvidos e publicados no meio acadêmico (SEABRA, 2001, 2007, 2015, 2017; CASTRO et al., 2001; BORGES et. al., 2001; SILVA, 2001; SOLIS et.al, 2014 e outros), contribuem para o desenvolvimento sustentável das áreas protegidas da natureza, através do planejamento, gestão e uso dos bens naturais.

O trabalho que ora apresentamos é parte sequencial do Estágio Pós-Doutoral "Análisis Comparativo de la Gestión Socioambiental en Unidades de Conservación de Chile y Brasil: Directrices Básicas para el Desarrollo del Ecoturismo", desenvolvido e executado através do Instituto del Patrimônio Turístico, da Universidad Central, Chile (SEABRA, 2015). O objetivo principal da pesquisa original consistiu em realizar uma análise comparativa dos procedimentos de gestão ambiental executados em alguns parques nacionais do Chile e do Brasil, representando diferentes biomas, com ênfase no patrimônio natural e cultural e gestão socioambiental. Acrescentamos à base de estudos dos parques nacionais, outras categorias de áreas protegidas da natureza, conforme explanação ao longo do texto. Em razão da complexidade do tema em sua dinâmica socioeconômica e ambiental, seguimos em busca de respostas para as hipóteses elencadas, inclusive incorporando outras áreas protegidas equivalentes àquelas então pesquisadas.

Derivada do nome arbóreo araucária, a Região de Araucanía está situada a uma distância aproximada de 700 quilômetros ao sul de Santiago, capital do Chile, compreendendo um vasto território limitado pelos rios Bio-Bio, ao norte, e Toltén, ao sul; a oeste com o oceano Pacífico, e, a leste, tangencia a linha fronteiriça andina com a Argentina. Denominada Pewen, no idioma mapungu (mapuche) a espécie Araucaria araucana é predominante na região andina setentrional do Chile e da Argentina. No habitat natural as altitudes superam 800 metros, os solos são rasos, associados aos afloramentos rochosos e congelados na maior parte do ano (Figura 1). 


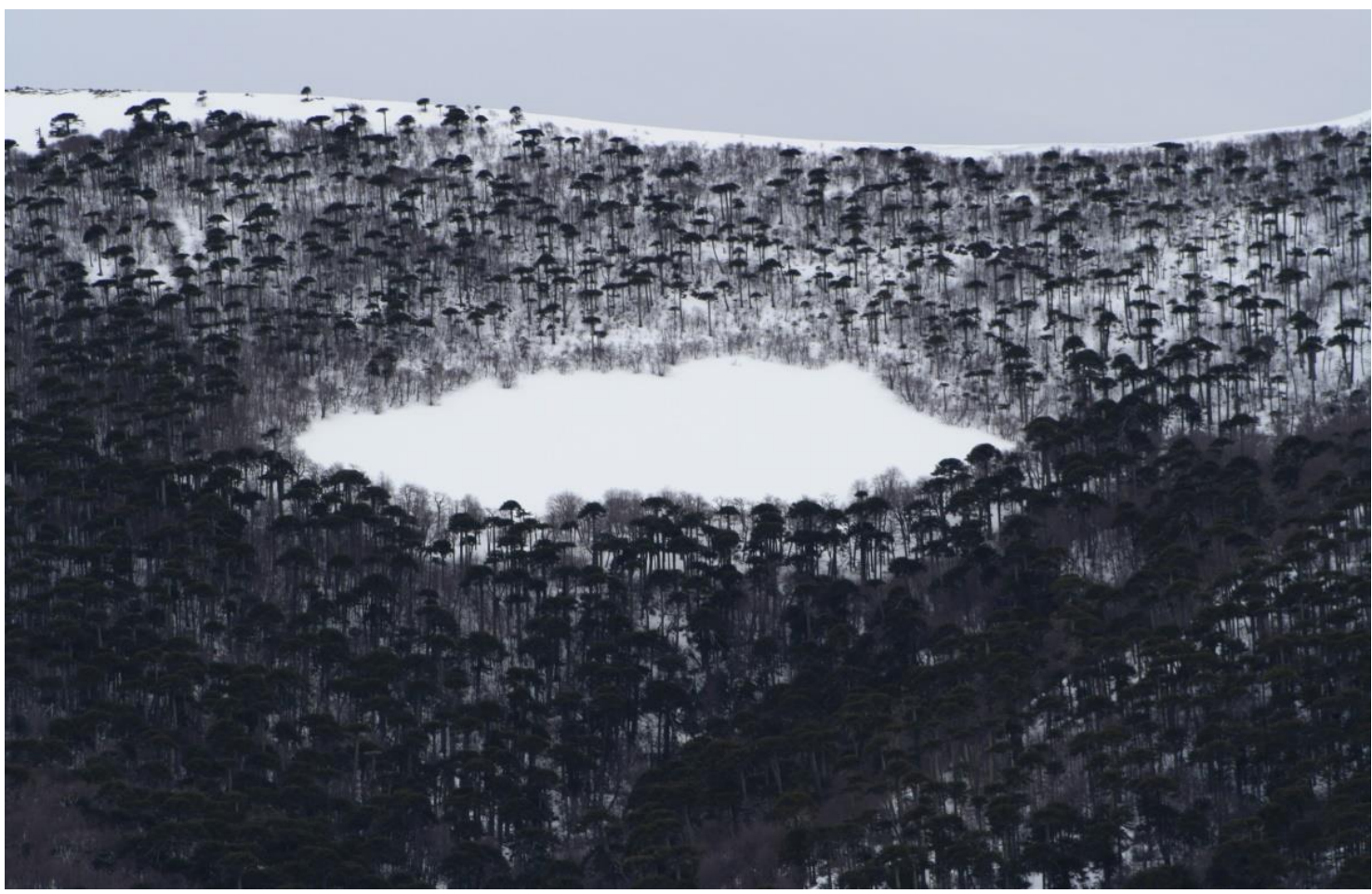

Fonte: Giovanni Seabra, outubro / 2014.

Em alguns setores, a ocorrência da araucária está associada a outras espécies, como a Lenga (Nothofagus pumilio). A araucária é uma árvore caducifólia da família Nothofagaceae nativa da cordilheira dos Andes, cuja ocorrência se estende desde as florestas temperadas do Chile e Argentina até a Terra do Fogo. De porte imponente, atinge 45 metros de altura, dois metros de diâmetro e longevidade de até 2000 anos. Registro vivo da Era Paleozóica, a espécie é endêmica nas áreas temperadas montanhosas da América meridional, cujas sementes compõem a dieta dos povos originários mapuche-puelche que habitam a região desde 10.000 anos ap.

São destaques nas paisagens pitorescas e diversificadas da Araucanía os colossais vulcões nevados, os majestosos bosques de araucária e os rios de águas rápidas que correm encaixados nos profundos cânions de paredões a pique. Nas paredes dos vales profundos, dezenas de camadas de paleossolos registram a paleohistória dos eventos vulcânicos e climáticos.

A topografia é típica da cordilheira dos Andes, caracterizada por altos picos e altiplanos compartimentados por desfiladeiros com encostas íngremes. Os cumes mais elevados correspondem aos vulcões Llaima (3.215m) e Lanin (3.776m). (Figura 2). 
Figura 2

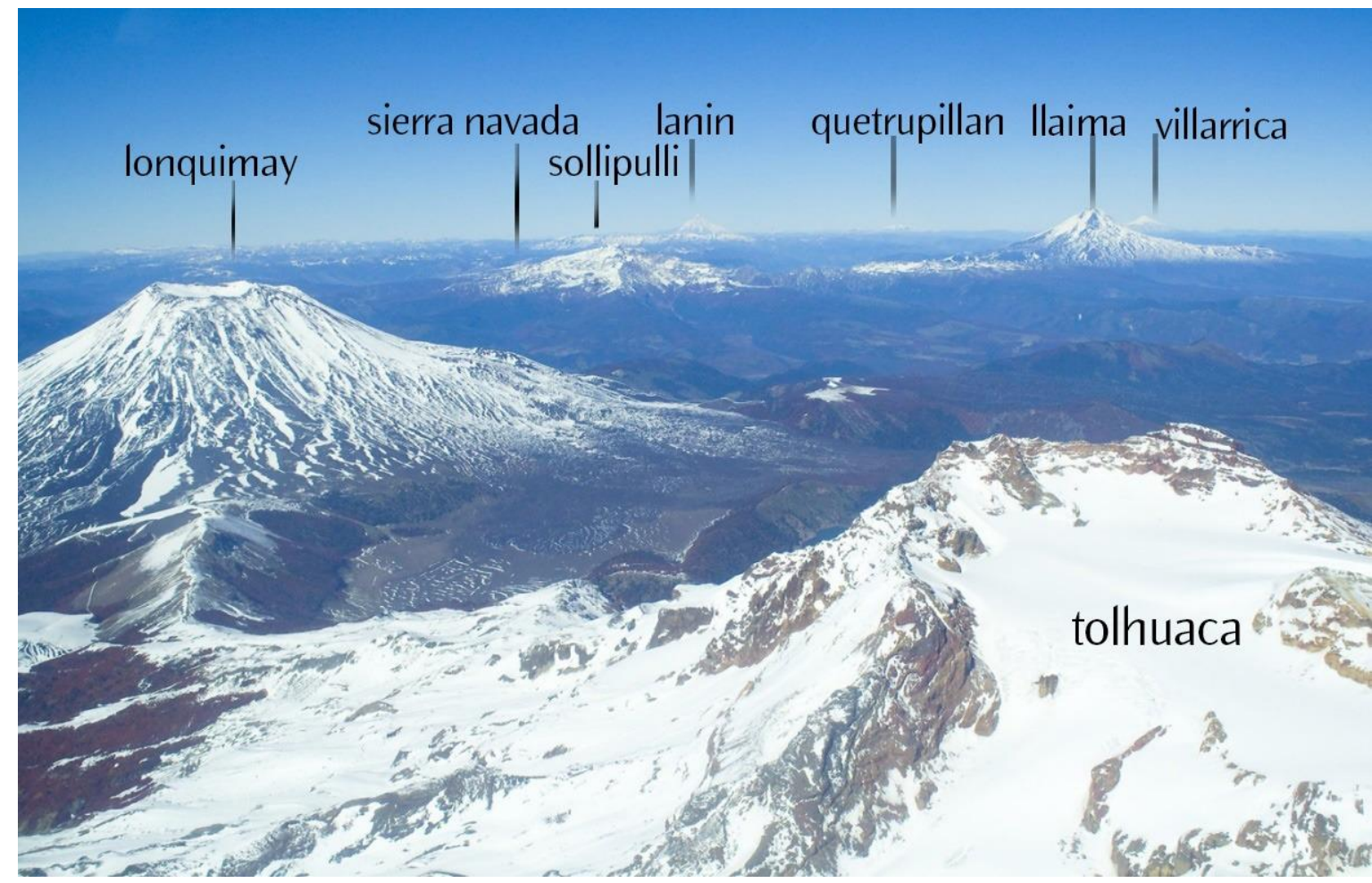

Fonte: Diego Stapafore, abril / 2012.

Existem diversos tipos de climas na Araucanía, com variação na direção norte-sul e do mar à cordilheira; há também uma série de microclimas segundo as peculiaridades topográficas. Assim, a Cordilheira de Nahuelbuta serve como uma barreira a barlavento das massas de ar úmidas oceânicas, produzindo uma área com menores precipitações na vertente oriental, a sotavento. Pela mesma razão, na Cordilheira dos Andes chove três a quatro vezes mais do que na Depressão Central. As maiores precipitações ocorrem nos meses de março e agosto, variando entre 2.500 e $3.500 \mathrm{~mm}$. As temperaturas mínimas atingem $4^{\circ} \mathrm{C}$, as máximas chegam a $23^{\circ} \mathrm{C}$ e a neve acumulada no solo alcança 2 metros de espessura.

\section{O MÉTODO}

A fim de compreender globalmente o objeto de estudo, a pesquisa ambiental adota uma metodologia focada na apreensão das características e arranjo sistêmico dos seus componentes. Para alcançar os objetivos propostos, o procedimento metodológico requer 
a integração das diversas áreas do conhecimento científico, através da unificação das metodologias específicas em torno de um procedimento metodológico mais abrangente.

O processo investigativo adotou uma metodologia integrada, reunindo diferentes campos das ciências, como a Geografia Física, Geologia, Biologia, Ecologia, Paisagismo e o Turismo. A pesquisa enfocou os aspectos geológicos, geomorfológicos e a sociobiodiversidade, que individualizam a paisagem, definindo o lugar turístico, bem como as contradições pertinentes ao modelo implantado. As diferenciações existentes na paisagem, em nível regional e local, que caracterizam o lugar, são espacialmente individualizadas em unidades geoecológicas para fins de planejamento ambiental e turístico. O ordenamento territorial, numa abordagem sistêmica e descentralizada, propicia a inclusão social, o desenvolvimento local e a integração regional (SEABRA, 2019).

Para o diagnóstico ambiental priorizou-se a observação de campo com a utilização do método DRP - Diagnóstico Rápido Participativo, fundamentado em dados primários e secundários, bem como o apoio técnico e científico de colaboradores acadêmicos, órgãos oficiais e a população local (SOLIS Et. all 2015).

No Chile foram visitados o Parque Nacional Isla de Pascua, P. N. Torres de Paine, P. N. Pan de Azucar, P. N. Llanos de Challe, P. N. Conguillio, P. N. Villa Rica, P. N. Alerce Andino, P. N. Vicente Pérez Rosales, P. N. de la Campaña, e também a extensa área da Araucanía delimitada para abrigar o recém criado Geoparque Kütralkura. Pesquisas desenvolvidas pelo autor, contemplando parques nacionais e áreas equivalentes do Brasil serviram como suporte comparativo dos dois países, no tocante á realidade ambiental das áreas protegidas.

\section{GEODIVERSIDADE, GEOCONSERVAÇÃO E GEOTURISMO}

Montanhas, vulcões, eventos tectônicos, estratos rochosos e solos compõem a peculiar geodiversidade da Araucanía. A geodiversidade, a geoconservação e o geoturismo são práticas centenárias de lazer envolvendo a contemplação e vivências junto à morfoesculturas rochosas e monumentos geológicos (Figura 3). 
Figura 4 - Vulcão Rukapillán (Casa dos Espíritos). Parque Nacional Villa Rica, Pucón, Chile.

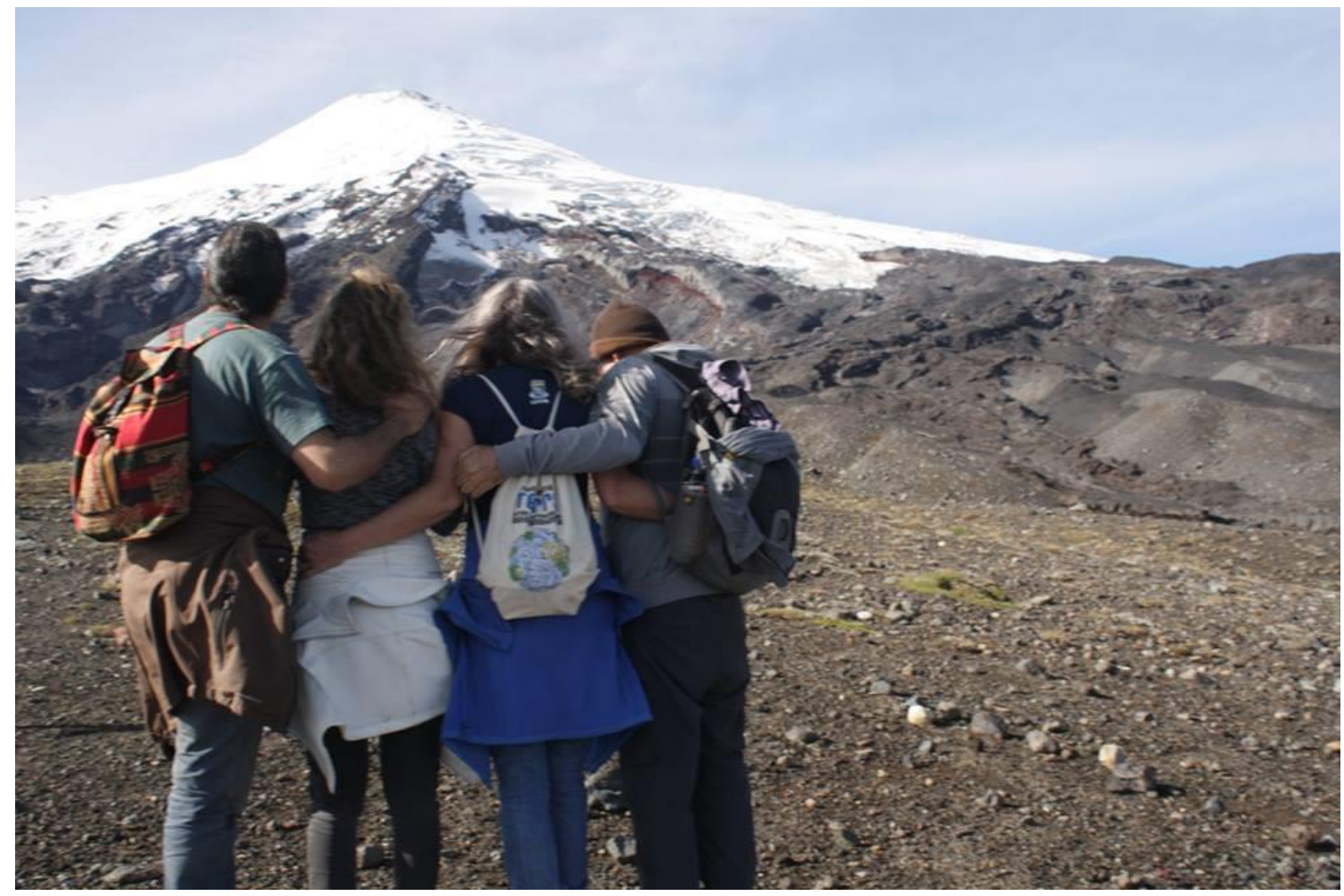

Fonte: Diego Stapafore, abril / 2014.

Segundo alguns autores, o conceito de geodiversidade surgiu em 1993, durante a Conferência de Malvern sobre Conservação Geológica e Paisagística, quando a Royal Society for Nature Conservations, do Reino Unido, apresentou a proposta de definição do termo, aceito desde então:

A geodiversidade consiste na variedade de ambientes geológicos, fenômenos e processos, que dão origem às paisagens, rochas, minerais, fósseis e solos, que são o suporte para a vida na Terra. (BRILHA, 2005, p. 17).

A geodiversidade, portanto, nos remete à diversidade de rochas, depósitos sedimentares e processos geológicos formadores e escultores das paisagens, servindo de substrato à biodiversidade e às ações humanas. A geodiversidade inclui também a interpretação da gênese das rochas, ou seja, os processos terrestres físicos e abióticos pretéritos, cuja existência é comprovada pelo registro geológico material que se verifica na atualidade (BORBA e SEL, 2018). 
A geoconservação, por sua vez, tem como objetivo a gestão do patrimônio geológico e os processos naturais a ele associados; pari passu, o geoturismo corresponde às viagens motivadas pela geodiversidade, nelas inseridas a cultura e a sustentabilidade dos povos residentes.

Geodiversidade, geoconservação e geoturismo são conceitos recentes no mundo acadêmico, cuja essência, tanto de um como de outro, todavia pertence ao lazer e imaginário de antigas civilizações europeias e asiáticas. O geoturismo é uma derivação do ecoturismo com ênfase nas morfoesculturas do relevo, incluindo informações sobre a gênese, estrutura e morfodinâmica da rocha. Existem roteiros turísticos implantados com objetivos geológicos, geomorfológicos, ecológicos, pedagógicos e científicos em várias regiões do planeta, muitos consolidados como destinos turísticos nos geossítios, geoparques, monumentos naturais e parques nacionais. Os geossítios são ocorrências de um ou mais elementos da geodiversidade, delimitados geograficamente, que se distinguem pelo valor singular científico, pedagógico, cultural e turístico. É destaque no geoturismo, não apenas as feições geomorfológicas, mas também as demais formas de superfície, como as montanhas, serras, vulcões, cânions, cavernas, depósitos vulcânicos, glaciais e fluviais, e também os registros de passagens dos povos ancestrais nas inscrições rupestres, chamadas pedras lavradas.

Vale salientar que o geoturismo, tal qual o conhecemos nos dias atuais e difundido pelas universidades no Brasil e no exterior, é uma prática consagrada há centenas de anos em outros países.

Já no século XIX o turismo geológico era uma forma de lazer contemplativo usual às margens do rio Elba, na Saxônia, atuais territórios pertencentes à Alemanha e República Checa, com destaque para as morfoesculturas em arenito e as pontes de pedra, onde está instalado o National Park Sächsische Schweiz. A paisagem estruturada sobre a rocha arenítica compreende a Bohemian National Park Region, onde as Montanhas de Arenito do Elba estendem-se por uma área de cerca de $700 \mathrm{~km}^{2}$ em ambos os lados do rio. As áreas protegidas estão localizadas em território checo e alemão, abrigando quatro áreas de conservação: duas no lado germânico da fronteira e duas no território checo. (Figura 5). 
O Nationalpark Sächsische Schweiz é um espaço geográfico diferenciado onde se insere uma paisagem harmoniosa formada de rochedos íngremes e torres de pedra, entremeados de desfiladeiros úmidos adornados por florestas, riachos e o povoamento humano tradicional, organizados num mosaico paisagístico multicolorido. O substrato consiste numa camada de arenito e quartzo, com espessura superior a 600 metros, formada durante o período Cretáceo e profundamente dissecada pelo rio Elba e seus afluentes, dando origem às exuberantes geoformas. É intrigante na região o fenômeno da inversão climática, onde as florestas alpinas da Europa Central são dispostas ao inverso das altas altitudes, crescendo no interior dos cânions profundos.

Figura 5 - Nationalpark SächsischeSchweiz, Alemanha.

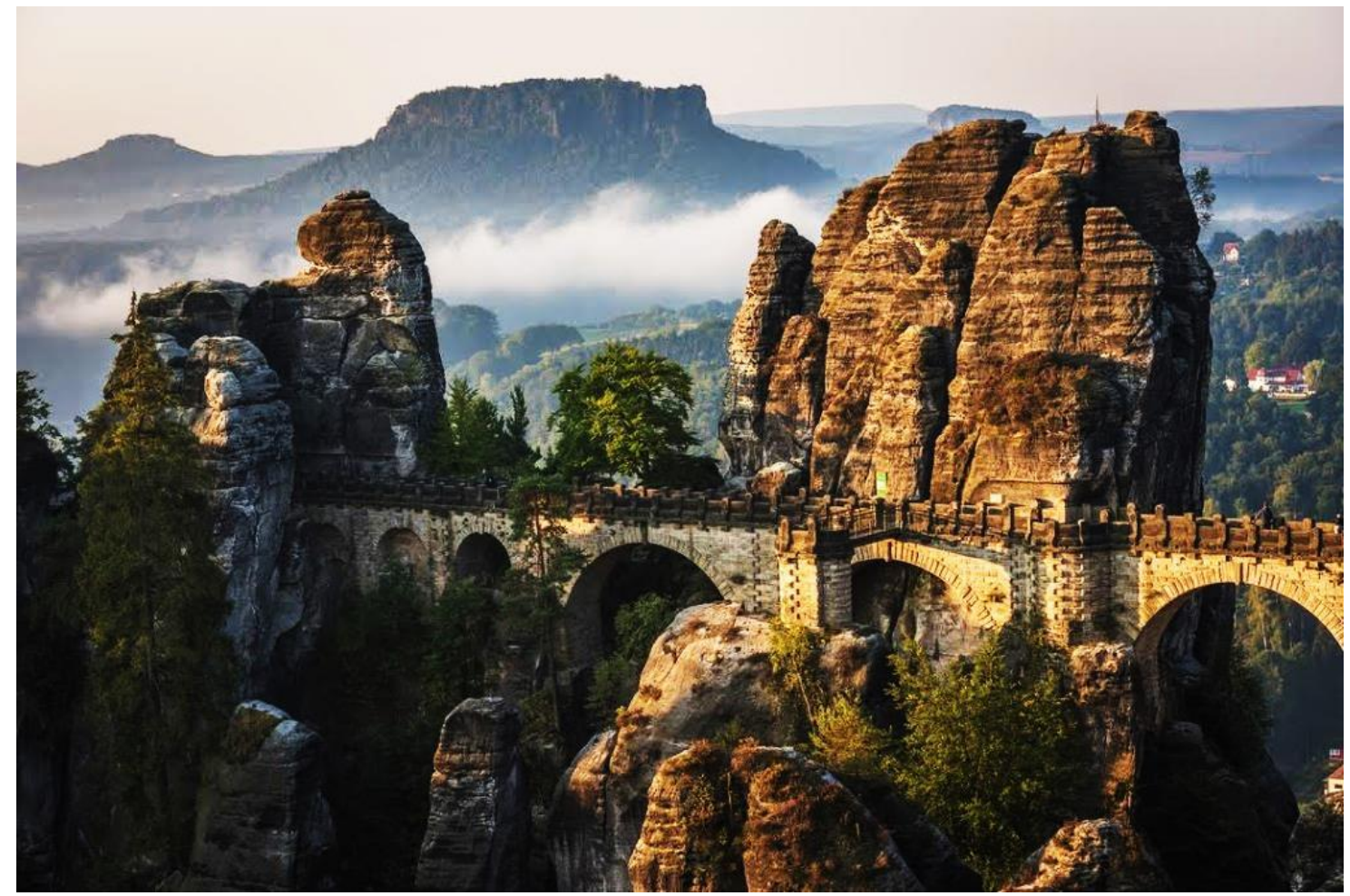

Fonte: NationalparkSächsischeSchweiz.html

O Saxonswitzerland National Park Centre, na pequena cidade de Bad Schandau, é o centenário centro de visitantes do Parque Nacional, contendo informações e orientação aos visitantes. Serviços de apoio (hotéis, pousadas, restaurantes) e de infraestrutura, como elevador, mirante, trilhas sinalizadas, pontes, e passarelas, foram instalados há mais de duzentos anos na unidade de conservação e entorno. As estruturas e equipamentos centenários para visitação pública são indispensáveis para manter o fluxo de turístico e 
promover o desenvolvimento regional. O êxito da implantação de parques nacionais, geoparques e unidades equivalentes dependem de investimentos em logística, equipamentos, serviços e a inclusão social da população local. (Figuras 6 e 7).

No Brasil, há décadas, geodiversidade, geoturismo e geoconservação, são conceitos relacionados à contemplação das morfoesculturas da natureza em unidades de conservação, como o Parque Nacional de Ubajara, no Ceará; o Parque Nacional de Sete Cidades, no Piauí; e o Parque Estadual de Vila Velha, no Paraná; fundados, respectivamente, nos anos de 1959, 1960 e 1966, só para citar alguns. Nessas e noutras áreas protegidas doo Brasil a população residente é empregada direta e indiretamente no atendimento e acompanhamento dos turistas.

Figura 6 e 7 As imagens revelam estruturas de acesso aos geomonumentos e os equipamentos turísticos (hospedagem e restaurante) para acolhimento dos ecoturistas, em 1886.
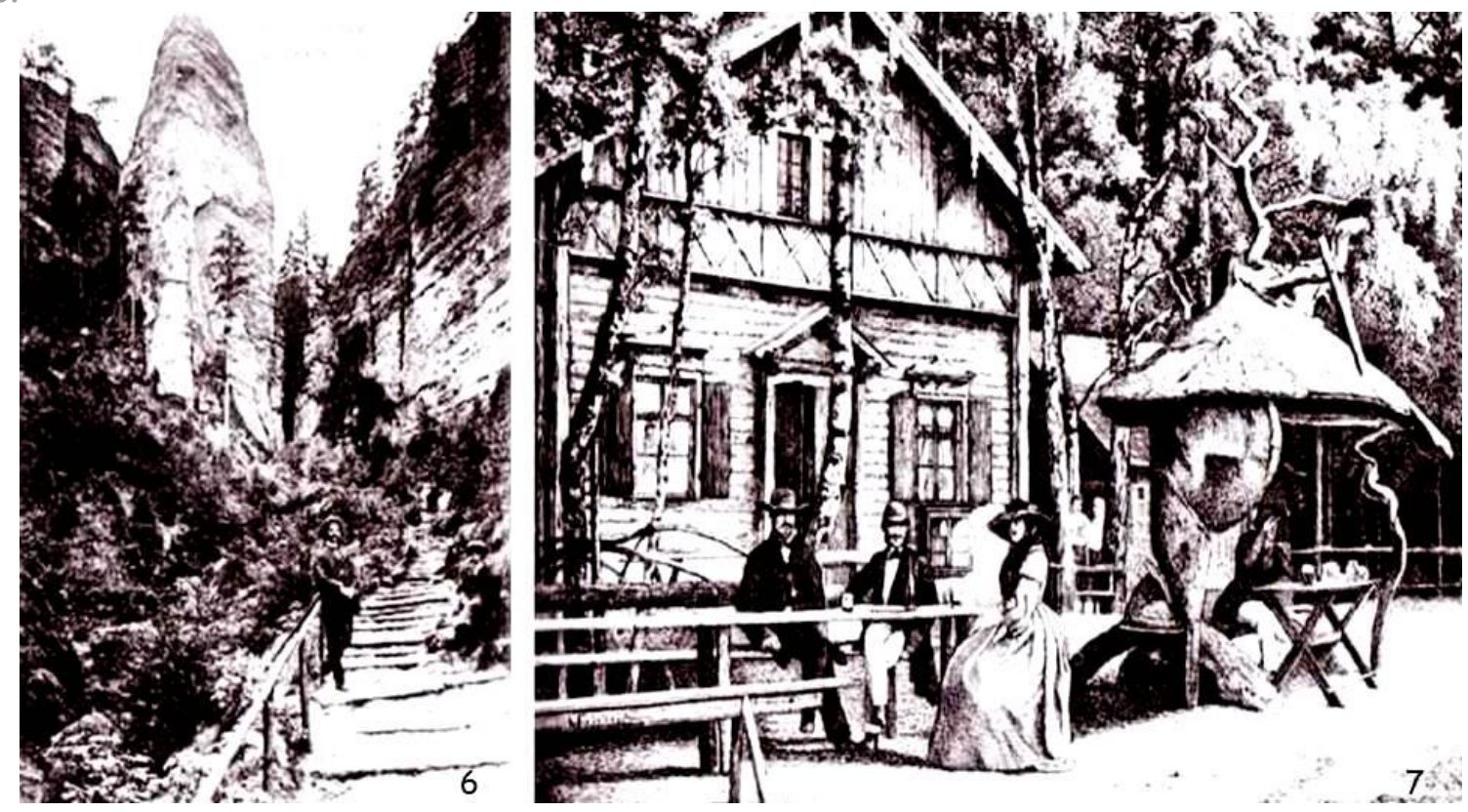

Fonte: Rölke, 2006b.

\section{A ARAUCANIA}

Voltando ao Chile, durante a colonização espanhola, os limites da Araucanía eram reconhecidos como território independente mapuche, em razão do poder de resistência das forças indígenas. Na Região Andina, o Império Colonial espanhol se estendia desde o Equador e Peru até o rio Bio-Bio, limite norte do território mapuche, e recomeçava a partir 
do rio Toltén, na fronteira sul da terra indígena, seguindo até a Terra do Fogo. Durante a guerra de conquista, os campos cultivados foram destruídos, as rukas (casas) e centros cerimoniais incendiados e o criatório animal saqueado. Após resistir a ocupação por mais de 300 anos, o povo mapuche capitulou perante as campanhas militares desproporcionais, acentuadas a partir de 1862. Com a pacificação dos mapuche, imposta pelo Governo do Chile, suas terras foram tomadas pelos colonos europeus e agricultores chilenos.

Em 1990, com o retorno à democracia, o Governo Chileno promulgou a Nova Lei Indígena (1993), que, apesar de ter sido elaborada de maneira participativa com as comunidades indígenas, não conseguiu reintegrar ao povo mapuche a posse de grande parte do seu território original. Ao contrário, no âmbito de uma política neoliberal multicultural (BOLADOS, 2012 apud REYES, 2019), a desapropriação de terras, a mudança no modo de produção e a pilhagem do território mapuche por empresas florestais e de energia hidrelétrica aumentou. Consequentemente, as organizações mapuche denunciam permanentemente o dano irreparável ao seu ecossistema e à cultura, reivindicando o direito à autonomia e autodeterminação (PAIRICAN, 2014; CALBUCURA, 2006 apud REYES, 2019).

Por seguinte, menos de $15 \%$ das terras araucanas pertence às comunidades mapuche e outros $20 \%$ às empresas florestais. Os desequilíbrios ambientais antrópicos são evidenciados com a drástica redução na biodiversidade florística e faunística e a escassez de água causada, principalmente, pelas monoculturas de eucaliptos e agravada com o aquecimento global. Cerca de 100.000 pessoas, em sua maioria mapuche, padecem com a falta d'água para o uso básico em diferentes zonas rurais devido ao impacto da monocultura e à mudança climática (NSC TOTAL, 2017). O Código da Água chileno, em vigência desde 1981, categoriza a água como um bem de consumo sujeito à lógica e às características do mercado. Entre os seus objetivos constam o registro dos direitos da água por particulares, estímulo ao mercado da água e a separação entre o domínio dos recursos hídricos e a propriedade da terra. O modelo de gestão da água ignorou completamente o meio ambiente e as necessidades sociais, incentivando a exploração demasiada dos recursos hídricos por empresas privadas. Em nível nacional, os principais consumidores são a agricultura (73\%), a indústria (12\%), a mineração (9\%) e a população humana (6\%). (OBSERVATÓRIO, 2020). 
Os conflitos políticos e socioeconômicos permanecem até os dias atuais, em razão de contendas territoriais envolvendo a exclusão social, e a resistência da língua, rituais e costumes ancestrais. Como saldo dos confrontos entre índios e não índios, principalmente empresários madeireiros e proprietários de terras, mais de duas centenas de caminhões e tratores foram incendiados nos últimos anos, de um lado, e, do outro, dezenas de centros cerimoniais queimados (EM, 2019). Vale salientar que isto ocorre numa das principais regiões turísticas do Chile, onde são implantados projetos de desenvolvimento sustentável econômico, social, cultural e ambiental.

Além das montanhas florestadas entremeadas de rios e lagos, o setor turístico regional é altamente lucrativo na exploração dos parques nacionais, monumentos e reservas naturais, estações de esqui, termas, hotelaria, restaurantes, cafés, e uma infinidade de serviços disponíveis ao turista. Entretanto, a alta lucratividade do turismo contrasta com o estado de pobreza das comunidades mapuche, sobretudo nas áreas rurais e nas periferias urbanas.

À parte, o turismo etnocultural indígena recebe poucos incentivos governamentais e, consequentemente, apresenta fluxo turístico reduzido, quando comparado ao turismo de massa que imprime fortes pressões e impactos socioambientais nas áreas protegidas da natureza. As belezas cênicas, estações de esqui, termas, trilhas e mirantes motivaram a visita de 491 mil turistas na Araucanía em 2018. Na semana santa de 2019, igual aos anos anteriores, a hotelaria registrou $90 \%$ de ocupação. No mesmo período, o Parque Nacional de Conguililo entrou em colapso demográfico, e o consequente fechamento ao público, devido ao grande número de visitantes ser muito superior à capacidade de suporte do Parque (EL AUSTRAL, 2019).

Por outro lado, neste ano de 2020, os parques nacionais do Chile, mais uma vez, entraram em colapso, ocasionado pelo fechamento das áreas protegidas em razão da pandemia provocada pelo novo corona vírus, o Covid -19 .

Em várias regiões do mundo, a exemplo de Cuzco, no Peru, e nas zonas rurais da Costa Rica (SEABRA e CRUZ, 2015), o aproveitamento das capacidades produtivas básicas impacta positivamente a economia regional, norteando a sustentabilidade local e evitando a implantação de grandes projetos turísticos social e economicamente excludentes. As empresas de turismo que operam nas pequenas localidades monopolizam e capitalizam 
todos os seus benefícios, restando muito pouco ou quase nada para os moradores. As grandes operadoras e redes hoteleiras são incentivadas através das diretrizes e ações do planejamento oficial, ao passo que os planos estratégicos governamentais vinculam-se às regras do modelo econômico concentrador de capital, menosprezando o desenvolvimento regional sustentável (SEABRA. 2007).

Na Região da Araucanía são encontrados a Reserva da Biosfera Araucária, os parques nacionais Conguillío, Villarrica, Huerquehue, Tolhuaca, Nahuelbuta, Reserva Natural Malcahuello, o Geoparque Kütralkura e outras áreas protegidas equivalentes. A região está inserida no Círculo de Fogo do Pacífico, frequentemente açoitada por abalos sísmicos, terremotos, tsunamis e erupções vulcânicas, destacando-se alguns dos vulcões mais ativos do Chile, como o Llaima, o Cordão Eruptivo Serra Nevada, o Complexo Lonquimay- Navidad, o Tolhuaca que e o Villa Rica ou Rukapillán, que significa Casa dos Espíritos, no idioma mapuche.

A Reserva da Biosfera Araucária (RBA) pertence à rede mundial de reservas da biosfera da UNESCO e possui uma área de 1.140 .000 hectares, correspondendo a 35,9\% do território regional, onde vivem 105 mil habitantes (11,7\% da população regional). A RBA abrange nove municípios e foi concebida com o objetivo de conciliar a conservação da diversidade biológica, o desenvolvimento econômico e social equilibrado e a manutenção de valores culturais da civilização mapuche (RBA, 2019).

Todavia os impactos socioambientais da superexploração econômica dos recursos naturais araucanos são evidenciados na região. A Reserva da Biosfera Araucária pertence à Ecorregião da Floresta Temperada Úmida Valdiviana, que está entre as áreas mais ameaçadas do Chile. Entre as causas mais prementes da destruição florestal somam-se os distúrbios antropogênicos, como a expansão urbana, o aniquilamento de habitats florestais indígenas, o pastoreio, os incêndios florestais, a introdução de espécies invasoras relacionadas à atividade humana e o plantio de monoculturas, sobretudo eucaliptos e pinus radiata (RBA, 2019).

Uma das características mais notáveis das florestas temperadas meridionais do Chile é o endemismo florestal e faunístico. Por outro lado, a exígua área de ocorrência da formação florestal em nível mundial justificou a sua inclusão nos 25 hotspots, sítios prioritários para 
conservação contendo os principais centros de endemismo de vertebrados terrestres e plantas do planeta.

O Parque Nacional Conguillio, cujo nome significa água com pinhões, na língua mapuche, está situado a uma distância de $148 \mathrm{~km}$ a nordeste da cidade de Temuco, principal centro urbano da Região. Em 1940 foi criado o Parque Nacional Los Paráguas, com 18.750 ha, o qual seria transformado, em 1950, na Reserva Florestal Conguillío, tendo sua área ampliada para 36.000 ha. Em 1987 houve nova expansão da área protegida e a requalificação territorial para Parque Nacional Conguillío, abrangendo 60.832 ha, incorporando as comunas de Curacautín, Lonquimay, (província de Malleco) Vilcún, Cunco e Melipeuco (província de Cautín). As paisagens pitorescas do Parque incluem os lagos, o vale do rio Truful-Truful, os bosques milenares de araucárias e o vulcão Llaima, um dos mais ativos do mundo, cujas lavas eruptivas consolidaram extensos pavimentos basálticos que se estendem por centenas de quilômetros.

No interior da unidade de conservação, um dos setores que mais atraem os visitantes é a subida na Serra Nevada, uma elevada cordilheira pré-andina com vistas panorâmicas do lago Conguillio, o vulcão Llaima e os imponentes bosques de araucárias (SEABRA, 2016). No período de maior fluxo de turistas, de novembro a abril, quando as temperaturas são mais amenas e as precipitações pluviais e quedas de neve reduzidas, o parque oferece serviços terceirizados como cabanas, camping, cafeteria, loja de conveniência, refúgios rústicos e sala para primeiros socorros. No setor Paráguas (guarda-chuva) está instalado o centro de esqui Las Araucarias, o segundo mais importante centro recreativo invernal da Araucanía. A maior parte dos serviços prestados ao público é terceirizado, ao passo que a atuação dos guardasparque, em número insuficiente para a fiscalização, é limitada a alguns setores da área protegida, especialmente junto às entradas onde há cobrança de ingressos. Em períodos de temperaturas extremas, quando ocorrem fortes precipitações de neve, pode-se observar a ausência dos funcionários do Parque Nacional. Não obstante a inexistência de fiscalização durante os extremos climáticos frios, em algumas ocasiões o Parque permanece aberto aos visitantes desavisados ou ousados, possibilitando visitas autoguiadas nos setores de alto risco (Figura 8). 


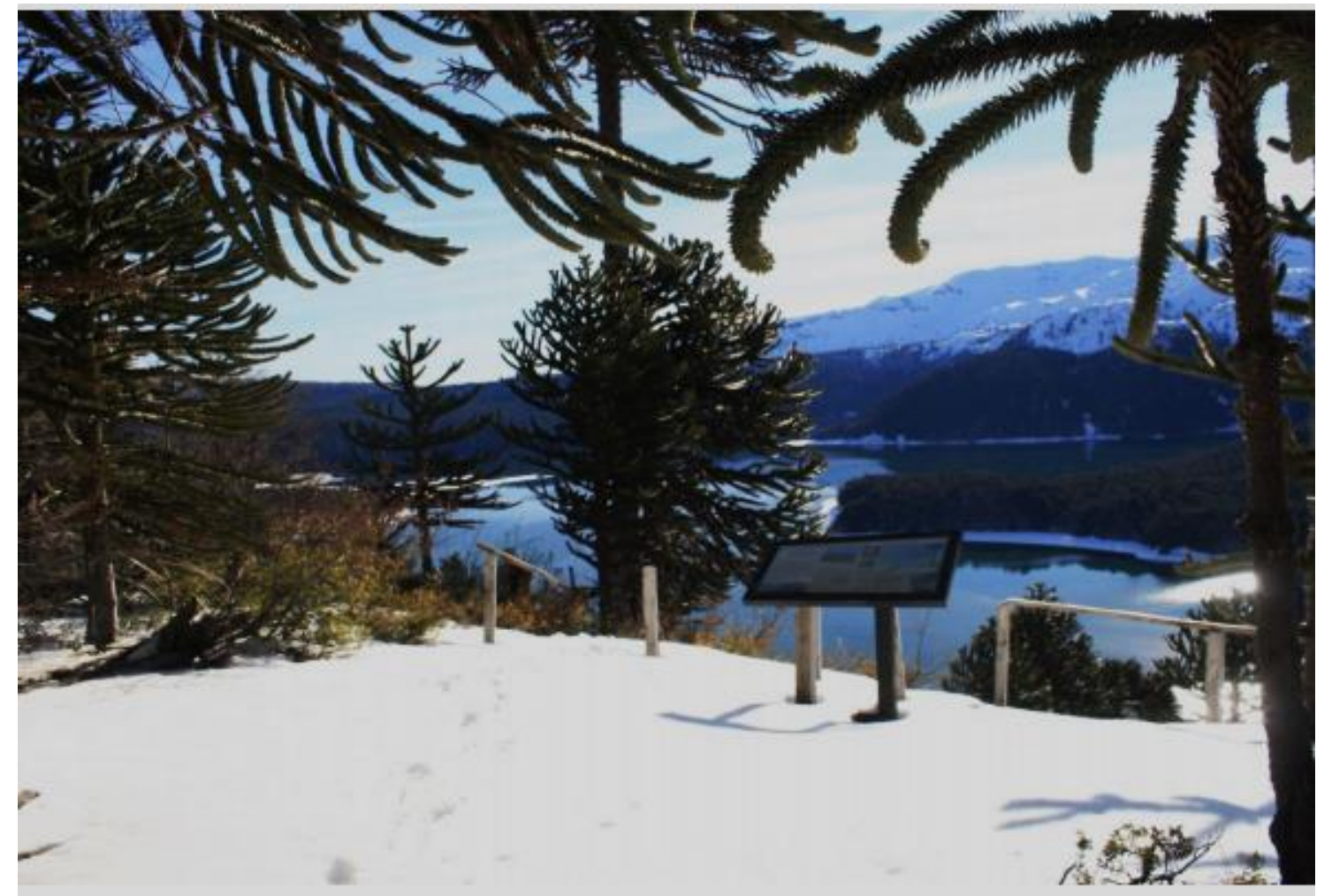

Fonte: Giovanni Seabra, outubro / 2014.

O Parque Nacional Huerquehue tem sua origem na Reserva Florestal fundada em 1912, e reabilitada para Parque Nacional do Turismo Benjamín Vicuña Mackena (o primeiro Parque Nacional do Chile), em 1925. Posteriormente, em 1967, a Unidade de Conservação foi reclassificada como Parque Nacional. O Parque está localizado a 35 km de Pucón na via de acesso ao lago Caburgua, ocupando uma área de 12.500 hectares, com altitudes variando de 700 a 2.000 metros. A área protegida possui um sistema de lagoas alimentadas por um significativo número de nascentes, rios e riachos, providos com o degelo nos altos picos da Cordilheira dos Andes e a neve acumulada durante o inverno. A intrincada rede de nascentes, rios e estuários, somada ao relevo marcado de vales estreitos e vegetação abundante configuram as 20 lagoas e lagos de origem glacial. Nas margens do lago Tinquilco está instalado o centro de informações, área para camping e trilhas autoguiadas interligando os demais atrativos turísticos.

Fundados em 1939, o Parque Nacional Nahuelbuta está localizado na província de Malleco, a uma distância de $35 \mathrm{~km}$ da cidade de Angol, na Cordilheira de Nahuelbuta. A unidade de conservação ocupa uma área de 5.432,20 hectares de superfícies montanhosas 
revestidas com araucárias, cujo principal objetivo é proteger os bosques da cordilheira costeira e ecossistemas associados. O Parque é servido por uma rede de trilhas e caminhos originários das estradas primitivas para a retirada de madeira, e, mais tarde, utilizada para a vigilância. Até 1936 as terras que atualmente integram o Parque Nacional Nahuelbuta pertenciam à Fazenda Vegas Blancas de propriedade de Don Joaquín Díaz Garcés. Da superfície total da fazenda totalizando 10.680 hectáres, foram destinados 5.150 ha à proteção da natureza. Antes da criação do Parque Nacional, havia na área intensa extração madeireira, ocasionando a devastação da floresta de araucária, carvalho e coigüe, uma vegetação estépica típica das montanhas. Além da exploração madeireira, o pastoreio intensivo era outra atividade econômica desenvolvida. Como agravante, o setor padecia constantemente com os incêndios, prática usual de preparo do terreno e renovação dos pastos. Os incêndios afetaram os bosques, os solos e a fauna, com reflexos na regeneraçaõ dos ecossistemas (FRANZ, 1970).

Tolhuaca, que em mapudungün significa frente de vaca, é o nome dado à Reserva Florestal da Província de Malleco, criada em 1.907. Posteriormente, em 1935, a área protegida foi transformada em Parque Nacional de Tolhuaca. A Unidade de Conservação está localizada na comuna de Curacautín, província Malleco, e abrange uma superfície de 6.374 hectares. As florestas de araucária (Araucaria araucana) formam a cobertura vegetal mais representativa, sendo também encontrada importante ocorrência das estepes endêmicas relictuais. No tocante aos mananciais hídricos, destacam-se a lagoa e o rio Malleco; a lagoa Verde, o vale do Malleco, a cachoeira da serpente e o cerro Amarillo. Nas imediações do parque estão instaladas as fontes termais e o vulcão Tolhuaca, o mais alto da região, com 2.806 metros de altitude. Nessa área existem instalações e equipamentos para excursões e camping.

Criada em 1968, a Reserva Nacional China Muerta está localizada nas comunas de Lonquimay (província de Malleco) e Melipeuco (província de Cautín). A Unidade de Conservação se destaca na proteção de espécies silvestres, como o puma, o pica-pau, a cobra de cauda curta e a rã de quatro olhos. Florísticamente há ocorrência de bosques exuberantes de araucária, cipreste da serra e lleuque. As principais trilhas que conduzem aos pontos e atrações turísticas são a Pedra Sagrada; Tres Arroyos; Raleo; Araucárias e 
Coloradito. Todavia, um desastre incandescente de grandes proporções atingiu a Reserva Natural China Muerta em 2015. Iniciado em 14 de março, o incêndio foi controlado no tardio 21 de abril do mesmo ano, ou seja, 45 dias após o início do fogaréu. De acordo com dados da CONAF, o fogo mais agressivo foi o que atingiu a China Muerta, que envolveu uma área de 6.599 hectares de um total de 12.825, ou seja, mais de 50\% da Reserva (Figura 9).

Figura 9. Parque Nacional China Muerta arrasado pelo fogo em 2015.

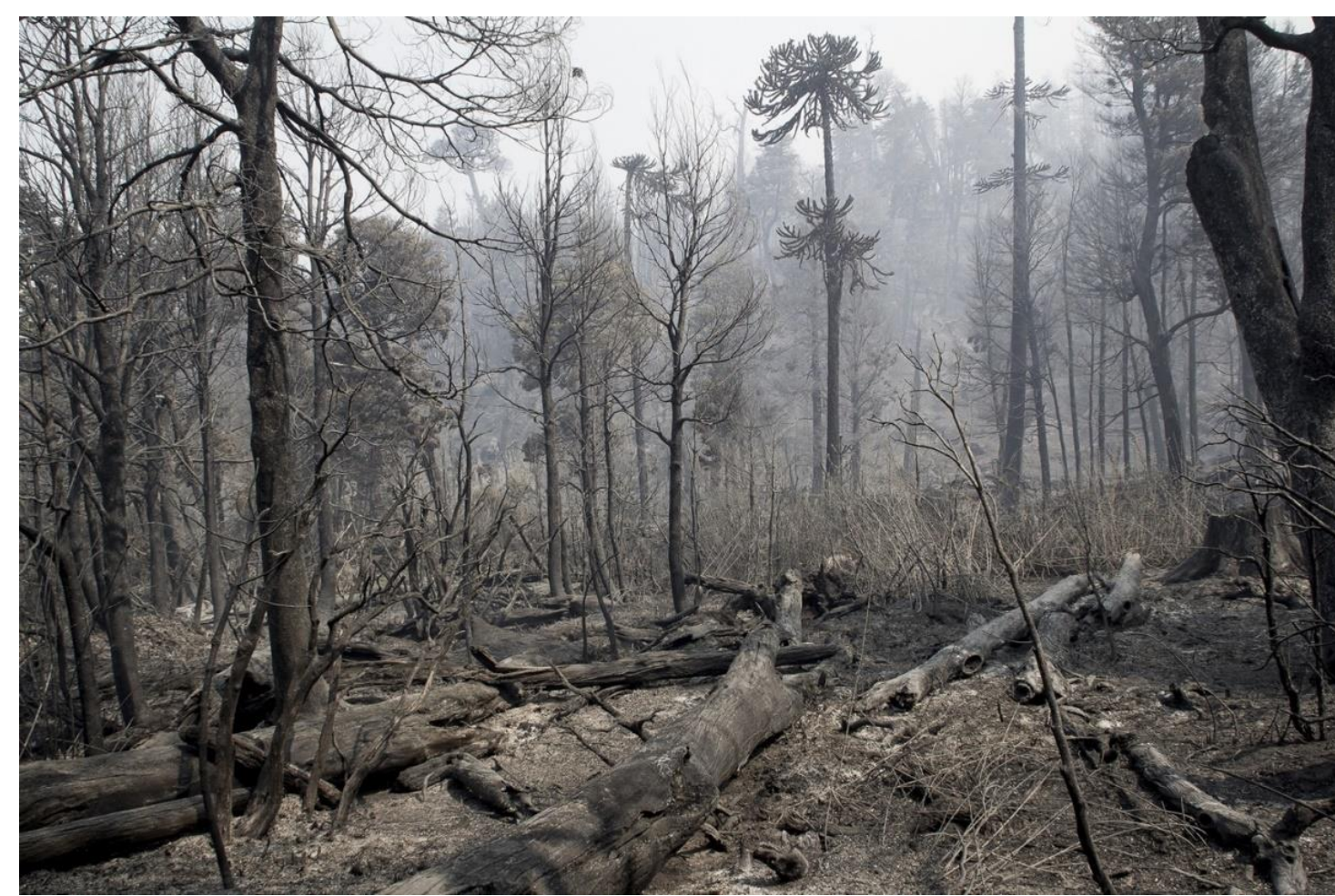

Fonte: Diego Stapafore, abril / 2015.

Por outro lado, o Parque Nacional Conguillío, que tangencia a Reserva Natural, foi menos afetado, já que o incêndio atingiu 62 ha do total de 60.832 hectares de sua área.

A Reserva Nacional Malalcahuello possui uma rede de trilhas autoguiadas para caminhadas. A principal delas conduz à cratera Navidad, um cone vulcânico erguido após a erupção deflagrada em 25 de dezembro de 1988. No povoado Malalcahuello, existe uma associação de artesãos pehuenches, que elaboram trabalhos em madeira de chunchín (picoyo), que em seu estado natural tem a forma de um tronco de madeira e o interior de cor âmbar vermelho. A matéria prima é encontrada no solo dos bosques milenários ou nos riachos. Também são confeccionados diversos tecidos e artigos de lã e couro. 
O extraordinário acervo geológico-geomorfológico da Araucanía, rico em geodiversidade e extraordinário valor geoturístico, motivou pesquisadores da Universidade Austral do Chile a apresentarem à Organização das Nações Unidas para a Ciência, a Cultura e a Educação - UNESCO o projeto de criação do Geoparque Kütralkura.

Em 17 de abril de 2019 a Rede Internacional de Geoparques Mundiais, vinculada à UNESCO anunciou o reconhecimento do Geoparque Kütralkura.

Um Geoparque é uma área com limites bem definidos, contendo um número significativo de locais de interesse geológico de particular importância, raridade ou relevância estética e paisagística, onde se destacam sua biodiversidade e aspectos históricos e culturais. Esses locais representam a memória da Terra e fazem parte de um conceito integrado de proteção, educação e desenvolvimento sustentável, onde são realizadas atividades geoturísticas e educacionais, por meio das quais são promovidas a proteção, a pesquisa e a disseminação do patrimônio geológico". (GEACHILE, SERNAGEOMIN, 2020).

A área protegida está localizada na região andina, entre $38^{\circ}$ e $39^{\circ}$ de latitude sul, ocupando um território de $8.100 \mathrm{~km}^{2}$, correspondendo a 25,45\% da superfície regional. A área do Geoparque é habitada por uma população de 50.000 pessoas, principalmente rural, com elevados índices de pobreza e analfabetismo. A etnia Pewenche representa 30\% da população total.

O Geoparque Kütralkura, que na língua ancestral mapuche significa pedras de fogo, tem como objetivo contribuir para o desenvolvimento social, cultural e econômico do território, coincidindo com os municípios de Melipeuco (5.313 hab.), Vilcún (20.887 hab.), Caracautin (18.135 hab.) e Lonquimay (9.099 hab.), segundo dados censitários de 2018. A criação do Geoparque visa também destacar características geológicas notáveis de origem vulcânica, tectónica e glacial, com destaque para os vulcões Villa Rica (Rukapillán), Llaima, Lonquimay, Sierra Nevada, e nevados de Sollipulli y Tolhuaca.

O Geoparque Kütralkura é resultado da iniciativa desenvolvida pelo Serviço Nacional de Geologia e Mineração (SERNAGEOMIN), em parceria com a Corporação Florestal Nacional (CONAF), o Governo Regional da Araucanía, Chile Innova, Coorporação de Fomento à Produção (CORFO), o Serviço Nacional de Turismo (SERNATUR), Corporação Nacional para o Meio Ambiente (CONAMA), o grupo Nuke Mapu Montanha, e os municípios de Melipeuco, Vilcún, Caracautin e Lonquimay. (GEACHILE, SERNAGEOMIN, 2020). 
Todavia, os frequentes e violentos confrontos entre os mapuche, de um lado, e a polícia e os empresários, do outro, põem em risco não somente a atividade turística tradicional e setores econômico associados, como também o recém implantado turismo étnico-cultural mapuche.

\section{PRESERVAÇÃO PATRIMONIAL E CONSCIÊNCIA SOCIOAMBIENTAL}

As necessidades humanas não têm limites na civilização ocidental, e, portanto, os estoques planetários para satisfazê-las nunca serão suficientes. Esta lógica do modelo de desenvolvimento ocidental resultou na depredação e esgotamento dos bens da natureza, explorados sem limites como recursos naturais. Os povos indígenas se consideram parte da natureza em vez de entendê-la como objeto de dominação. Por conseguinte, não aspiram a maximizar a rentabilidade dos recursos de curto e médio prazo, segundo o modelo capitalista de acumulação. Na lógica indígena, a distribuição de bens, produtos e serviços, está acima do acúmulo de riquezas. Para eles, a economia não pertence a uma dimensão separada do povo, e sim a um sistema equitativo contextualizado nas relações sociais comunitárias. Na cultura mapuche, a reprodução do trabalho ocorre através do conhecimento transmitido pelos pais e avós. Assim, desempenham atividades diversas, como a caça, a pesca, a coleta de frutos e sementes, o trato com o gado, a tosa das ovelhas, a elaboração de produtos utilitários e decorativos, a costura de roupas e agasalhos, o preparo da comida e a construção de casas.

Na região litorânea da Araucanía, especialmente na área compreendida entre Puerto Saavedra e o Lago Budi, foi implantada a Rota Turística Etnocultural Mapuche. Na zona turística, os visitantes podem vivenciar várias experiências com o povo mapuche, como as manifestações culturais, o trabalho e hábitos cotidianos, como atividades rurais, artesanato, gastronomia e excursões nos arredores. O etnoturismo mapuche é fundamentado na cosmogonia dos povos originários, traduzida na religiosidade e costumes, que permite aos visitantes vivenciarem o modo de vida ancestral, dormindo em uma ruka (habitação tradicional) e compartilhando os afazeres do dia-a-dia. São ítens da gastronomia tradicional mapuche as empanadas de changle, um cogumelo nativo e os pinhões salteados, entre 
outras iguarias. Os serviços de hospitalidade são oferecidos no interior das rukas, adaptadas para o acolhimento do turista, cujo interior é provido de cama, fogo de chão e mobília rústica, conforme os costumes mapuche (Figuras 9 e 10).

Figura 10. Ruka mapuche. Puerto Imperial, Chile.

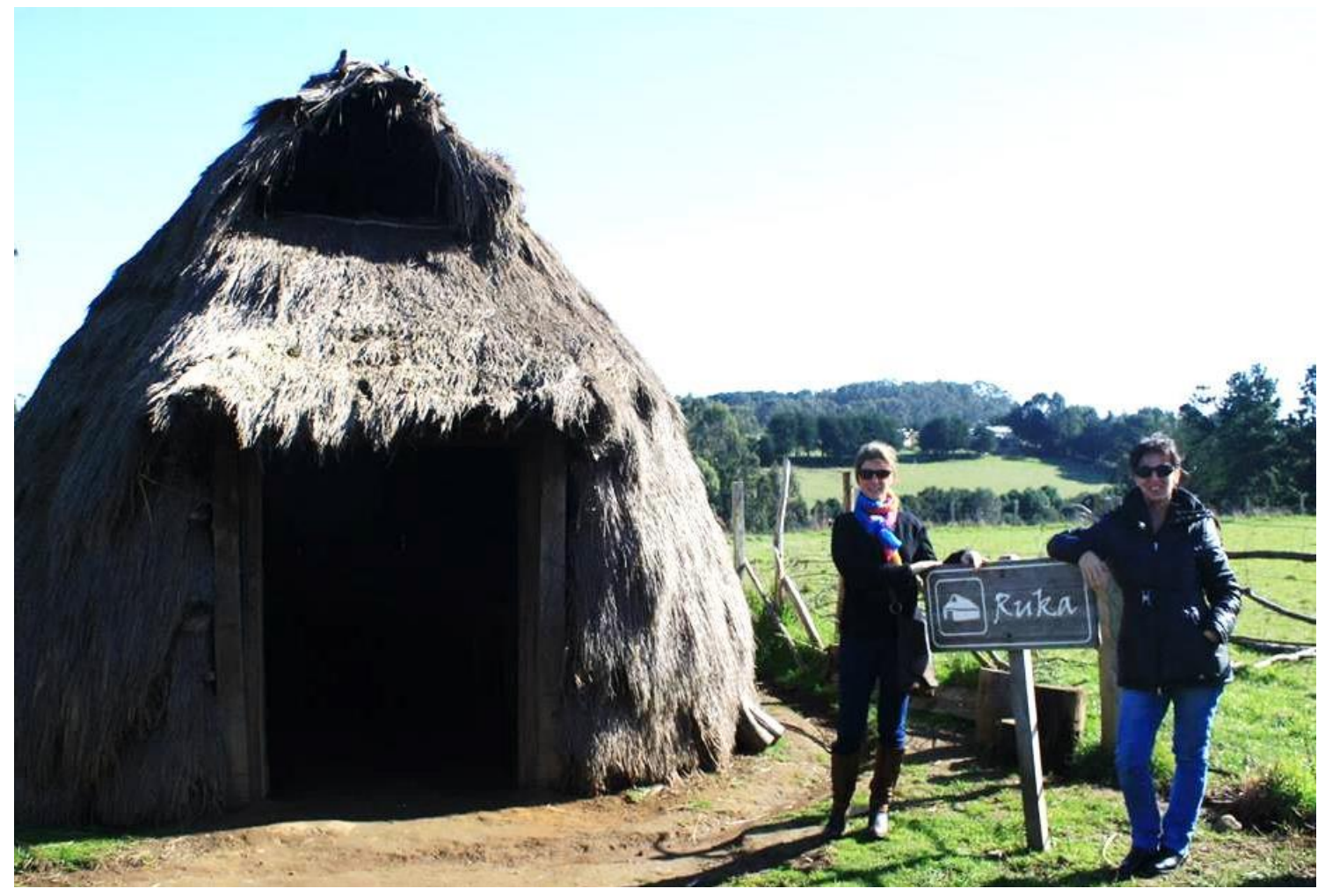

Fonte: Giovanni Seabra, outubro 2014. 


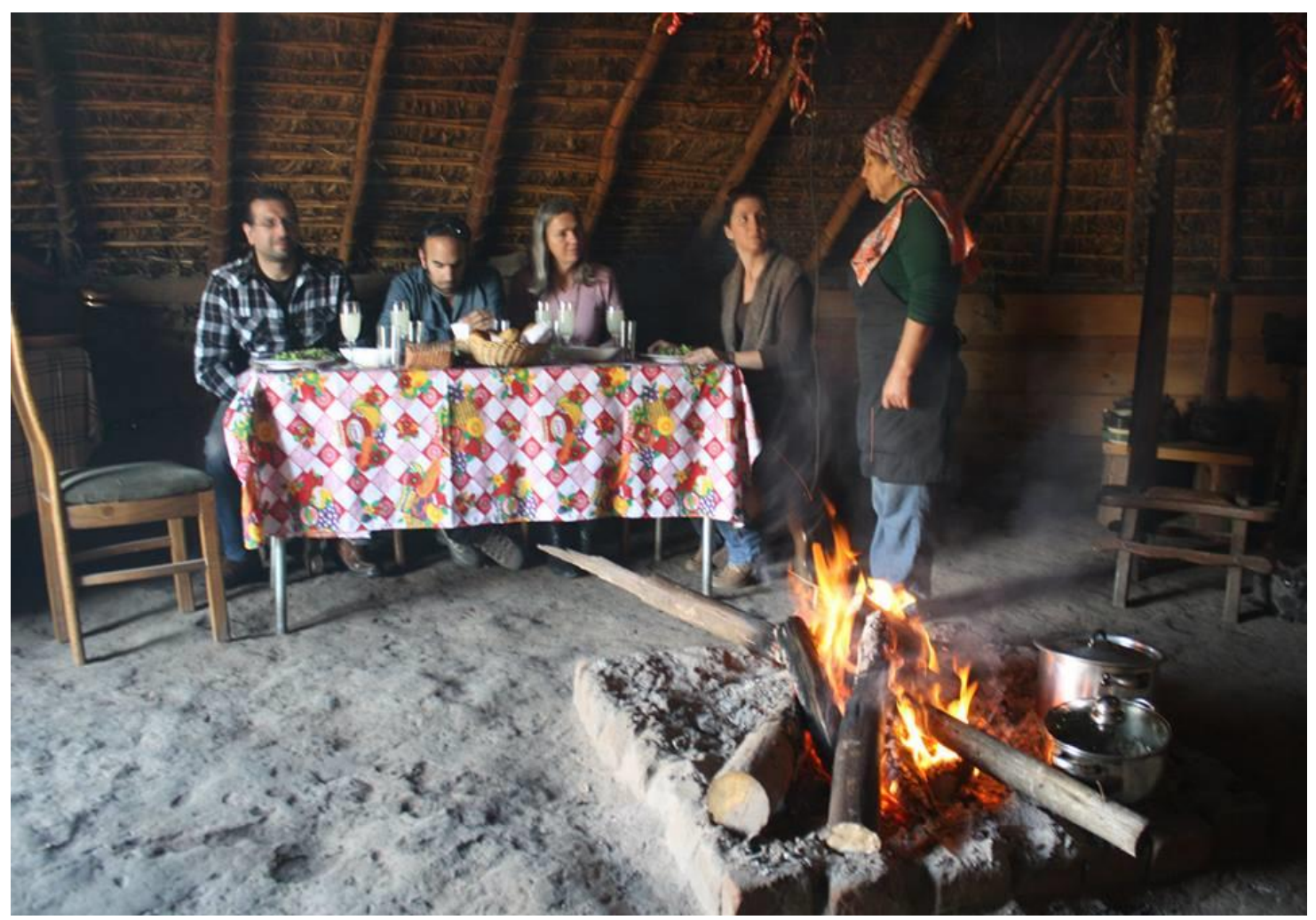

Fonte: Giovanni Seabra, abril 2016.

\section{REFERÊNCIAS}

ALFAMA, V. I. B.. Patrimônio Geológico da Ilha do Fogo (Cabo Verde): inventariação, caracterização e propostas de valoração. Tese de Doutorado. Universidade do Minho, Portugal, 2007.

BORBA, A. W., SELL, J. C. Uma reflexão crítica sobre conceitos e práticas da geoconservação. In Geographia Meridionalis. v. 04, n. 01. Jan-Jun/2018. p. 02-28.

BORGES, L., MARIANO, G., BARRETO, A.. Vale do Catimbau: Geologia e Turismo. Anais do I Simpósio Nordestino de Turismo Sertanejo. João Pessoa: UFPB, 2001.

BRASIL. Sistema Nacional de Áreas Protegidas. Brasília, 2000.

BRILHA, J. Patrimônio Geológico e Geoconservação: A Conservação da Natureza na sua Vertente Geológica. Braga - PT: Palimage Editores, 2005. 
CASTRO, C., BORGES, L., BARRETO, A., BRITO., S.. Turismo Geocientífico: A Província Pegmatítica da Borborema - Paraíba de Rio Grande do Norte. Anais do I Simpósio Nordestino de Turismo Sertanejo. João Pessoa: UFPB, 2001.

CONAF. Plano de Manejo do Parque Nacional Tolhualca. Santiago, 2014.

CONAF. Plano de Manejo do Parque Nacional Neuerquehue. Santiago, 1998

EL AUSTRAL. CONAF limitó aceso a Conguijillo por colapso. Temuco, 22 de abril de 2019.

FRANZ, R. M.. Plano de Manejo do Parque Nacional Nahuelbuta. Monografia de Graduação. Departamento de Engenharia da Universidade do Chile, 1970.

ORTIZ, M. G.. Araucanía Chile: patrimônio natural y cultural de sus territórios. Santiago de Chile: Pehuén, 2011. 320p.

PEREIRA, R. G. F. A.. Geoconservação e desenvolvimento sustentável na Chapada Diamantina (Bahia - Brasil). Tese de Doutorado. Universidade do Minho, Portugal. 2010. 295p.

REYES, A. A. Et. All. Identidad étnica mapuche e imaginarios sociales del bienestar en la región del Biobío, Chile. In Psicologia \& Sociedade. Vol. 31, p. 1-18. Belo Horizonte, 2019.

RÖLKE, P.. Wander \& Naturfüher: Sächsiche Schweis. Band 1. Dresden: Berg- \& Naturverlag Rölke, 2006a.

RÖLKE, P Wander \& Naturfüher:Sächsiche Schweis. Band 2. Dresden: Berg- \& Naturverlag Rölke, 2006b.

SEABRA, G. F.. Geodiversidade e geoturismo no estado de Roraima. Revista Eletrônica Casa de Makunaima. Ed. 3. Vol. 3, p. 63-68. Rio Branco: Editora UERR, 2019.

SEABRA, G. F Chapada Diamantina: o falso brilhante. Ituiutaba: Editora Barlavento, 2017.

SEABRA, G. F. O capital natural nas áreas protegidas do Brasil e Chile. In SEABRA, Giovanni F. (org.). O Capital Natural na Economia Global. p. 07-27. Ituiutaba: Editora Barlavento, 2016. 
Giovanni F.. Análises comparativo de la gestión socioambiental en unidades de conservación de Chile y Brasil: Directrices básicas para el desarrollo del ecoturismo. Informe Pós - Doctoral. Santiago: Universidad Central / IPT, 2015.

Giovanni F Pesquisa Científica: o método em questão. $2^{a}$ edição. João Pessoa: Editora Universitária da UFPB, 2009.

Giovanni F. Potencial Geoturístico no Nordeste Brasileiro. Caminho das Pedras: a paisagem sertaneja e o lugar do turismo. In Anais do I Simpósio de Geografia Física do Nordeste. Crato, 2007.

Giovanni F Ecos do Turismo: O Turismo Ecológico em Áreas Protegidas. Campinas: Papirus, 2001.

SEABRA. G. F. e CRUZ, J. C. P. El turismo em espacios rurales desde la perspectiva empreendedora em los processos de la nueva ruralidade: el caso de Guanacaste, Costa Rica. In Revista Conceitos. Edição No 22, vol. 1. p. 69-77. João Pessoa, 2015.

SOLIS, M. J. et.all. Evaluación multicriterio de la potencialidad turística de um territorio. caso de estudio Parque Nacional Pan de Azúcar, Región de Atacama. Chile. In SEABRA, G. F. (Org.). Terra - saúde ambiental e segurança alimentar. Vol. II. p. 760-785. Ituiutaba: Editora Barlavento, 2015.

SCHILLING, M.I; TORO, K.; CONTRERAS P.,et. all.. Geoparque Kütralkura: Património geológico para el desarrollo sustentable de la Región de la Araucanía. Santiago: Gobierno de Chile / SERNAGEOMIN, 2008.

Consultas na WEB:

http://www.subdere.gov.cl/división-administrativa-de-chile/gobierno-regional-de-laaraucania. Acessado em 18/07/2020, às 10:50.

https://www.observatorio.cl, acessado em 17.07.2020, às 09:30.

https://countrymeters.info/pt/Chile, acessado em 02/09/2019, às 10:00. http://geachile.sernageomin.cl/. Acessado em 15.07.2020, às 16:30hs. http://rbaraucarias.cl/rbaraucarias, acessado em 25.04.2019, às 18:45. https://www.ruta-patagonia.com/Guia-de-Parques-Nacionales, acessado em 26.04.2019, às 10:00. 
https://www.em.com.br, acessado em 26.04.2019, às 16:00.

https://www.nationalpark-saechsische-schweiz.de, acessado em 01.05.2019, às 16:00. http://www.conaf.cl/parques-nacionales, acessado em 01.05.2019, às 23:00. https://www.nsctotal.com.br, acessado em 20.09.2017, às 16:00. 